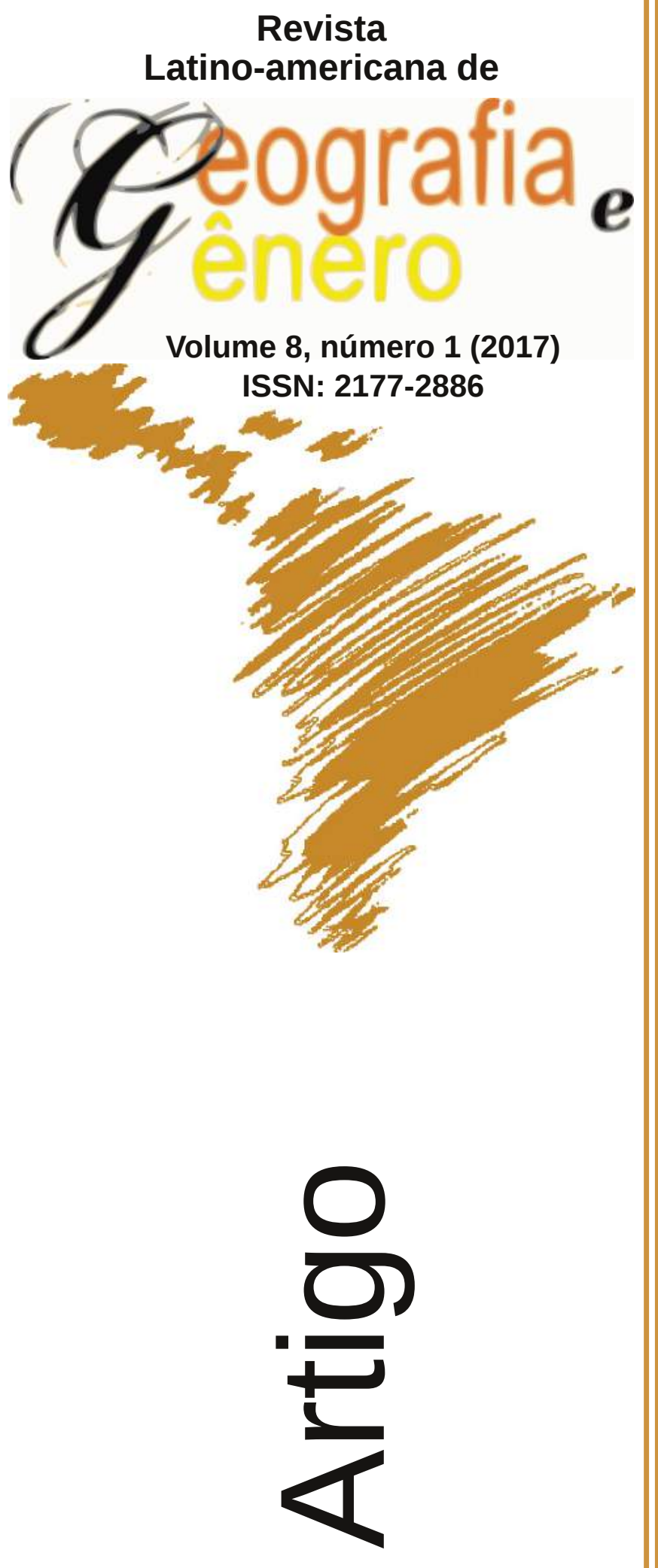

Trayectorias Educativas de las Personas Trans en Situación de Prostitución: Dilemas y Desafíos en el Norte Argentino

Trajetórias Educativas das Pessoas Trans em Situação de Prostituição: Dilemas e Desafios no Norte Argentino

Educational Trajectories of Trans People in Prostitution: Dilemmas and Challenges in the North Argentinian

Irma Elizabeth Chazarreta

Universidad Nacional de Santiago del Estero Argentina

irma939@hotmail.com

Como citar este artigo:

CHAZARRETA, Irma Elizabeth. Trayectorias Educativas de las Personas Trans en Situación de Prostitución: Dilemas y Desafíos en el Norte Argentino. Revista Latino Americana de Geografia e Gênero, v. 8, n. 1, p. 354-367, 2017. ISSN 21772886.

Disponível em:

http://www.revistas2.uepg.br/index.php/rlagg 


\title{
Trayectorias Educativas de las Personas Trans en Situación de Prostitución: Dilemas y Desafíos en el Norte Argentino
}

\author{
Trajetórias Educativas das Pessoas Trans em Situação de Prostituição: \\ Dilemas e Desafios no Norte Argentino
}

\section{Educational Trajectories of Trans People in Prostitution: Dilemmas and Challenges in the North Argentinian}

\section{Resumen}

En el presente trabajo se propone dar cuenta cómo las personas en situación de prostitución han sido educadas en materia de sexualidad, en el ámbito familiar y la escuela. Cuyas instituciones producen, reproducen y mantienen el orden social establecido por la cultura patriarcal, en la que rigen normas que definen a los varones y a las mujeres. Por lo tanto, quienes adoptan identidades de género diferentes a lo aceptable son moralmente rechazadas; así las personas trans recurren a la prostitución como única actividad posible de realizar por su condición de género. Estas reflexiones son parte de un trabajo de investigación realizada a personas trans en situación de prostitución en Santiago del Estero-Argentina que tiene como instrumento de recolección datos de historias de vida.

Palabras-Clave: Género; Personas Trans: Trayectorias; Educación; Prostitución.

\section{Resumo}

No presente artigo de propõe compreender como as pessoas em situação de prostituição tem sido educadas em matéria de sexualidade, no ambito familiar e na escola. Cujas instituições produzem, reproduzem e mantem a ordem social estabelecida pela cultura patriarcal, na qual regem normas que define aos homens e mulheres. Por outro lado, aqueles que adotam identidades de gênero diferentes ao aceitável são moralmente rejeitadas. Assim, as pessoas trans recorrem a prostituição como única atividade possível de realizar sua condição de gênero. Estas reflexões são parte de um trabalho de investigação realizada a pessoas trans em situação de prostituição em Santiago del Estero, Argentina, que tem como instrumento que tiene como instrumento de coleta dados de histórias de vida.

Palavras-Chave: Gênero; Pessoas Trans; Trajetórias; Educação; Prostituição.

\begin{abstract}
In this paper, we propose to account how people in prostitution have been educated in the field of sexuality, both in family and in school. Institutions which produce, reproduce and maintain the social order established by the patriarchal culture, which is ruled by patters that define man and women's roles. Therefore, those who adopt different gender identities than acceptable are morally rejected; consequently, trans people have to resort to prostitution as the only possible activity performed by their gender. These reflections are part of a research on transsexuals in prostitution in Santiago del Estero, Argentina, which uses as its instrument collection data of life stories.
\end{abstract}

Keywords: Gender; Trans People; Trajectory; Education; Prostitution. 
El feminismo a lo largo de su historia ha logrado cambios sociales, económicos, políticos, culturales y simbólicos; todos ellos, orientados hacia la conquista de derechos de las mujeres y la igualdad entre los géneros. Sin embargo, aún en la cultura patriarcal como la nuestra, coexisten ideologías tradicionales donde las mujeres y las minorías sexuales experimentan a diario situaciones de asimetrías, subordinación y dominación. Donde aún se concibe la sexualidad como un tema tabú, ligado a la genitalidad y a las relaciones sexuales. En efecto, existen diversos mitos y estereotipos en torno al tema que incide en el comportamiento de varones y mujeres.

La escuela en tanto lugar de socialización de los/as niños/as es un espacio donde se produce y reproduce la organización social; quienes irrumpen con ese orden son consideradas personas moralmente inaceptables. En este sentido, las personas trans ${ }^{1}$ son un ejemplo de ello, ya que no cumplen con la función social del varón o de la mujer, como únicas opciones en esta sociedad dicotomizante. Siguiendo la lógica, este grupo se encuentran fuera de la norma, por lo que la escuela se ve obligada hacer cumplir la misma, a través de ciertas reglas que corrijan o molden las conductas de los/as educandos/as.

El presente artículo es producto de una investigación más amplia en el marco de mi tesis de maestría llevada a cabo en Santiago del Estero-Argentina, donde se entrevistaron a personas trans que ejercen la prostitución. Se trata de un estudio con abordaje cualitativo del problema, basado en la indagación no estructurada sobre las historias de vida tal como son relatadas por los propios sujetos. Dirigidas a captar información personal y contextual de cada caso en un marco de respeto y privacidad, consensuando el propósito y los fines de la investigación. Desde este escenario se desprende el siguiente escrito, que tiene como objetivo describir las trayectorias educativas de las personas con identidades de género distintas a la heteronormativa. Asimismo, describir los significados adquiridos en torno al género que han atravesado la vida de las personas trans identificando las marcas que han producido dichos significados en la etapa escolar. De esa forma, analizar las causas por las que ingresan a la prostitución.

Las personas que forman parte del estudio pertenecen a la organización ATTTA (Asociación de Travestis, transexuales y transgéneros en Argentina) (Sede Santiago) y DIVAS (Diversidad valiente santiagueña), con quienes hace más de cinco años, se viene participando en diversas acciones como reuniones, marchas del orgullo gay, reclamos, y eventos sociales (casamientos, cumpleaños). Espacios que además de brindar datos que son registrados en el cuaderno de campo, posibilitan una mayor integración al grupo y en

1 En torno a las identidades de género, hay un debate político al interior de las organizaciones civiles, que en este trabajo no haré referencia. Sin embargo, utilizo para este escrito "personas trans" porque así se identifica la mayoría que forma parte del estudio. Se entiende por trans, a la persona cuya identidad de género implica un cuestionamiento del esquema binario varónmujer, e incluye diversas identidades. No utilizo "mujeres trans" porque al momento de entrevistar no todas se sienten identificada con esa categoría, se encuentran en proceso de construcción de la identidad donde en algunos casos no tienen identificado claramente a que género pertenecer o simplemente no quieren encasillarse en categorías sino vivir su identidad como la siente, aunque su apariencia física, y el nombre adoptado sea femenino. 
consecuencia, genera confianza para que se sientan cómodas y tranquilas al contar situaciones de la vida personal que en otro contexto no sería posible.

He tenido la oportunidad de entrevistar (en profundidad) aproximadamente 15 personas consideradas clave del tema, con las que, ha sido necesarios varios encuentros. Las entrevistadas viven en Santiago del Estero ubicadas en diferentes puntos del espacio social y la mayoría provienen del interior de la provincia. A través de la muestra se pretendió conocer una multiplicidad de trayectorias trans, por lo que se seleccionaron personas de diferentes edades, oficios y capitales económicos, culturales y sociales (BOURDIEU, 1980).

La mayoría de las entrevistadas se encuentran en un rango etáreo que va de los 28 a los 60 años de edad, solo una de ellas tiene 18 años al momento de la entrevista. La mayoría abandono sus estudios en el nivel secundario a causa de la violencia y discriminación sufrida en el colegio. Actualmente, la mayoría ejerce la prostitución en las calles de Santiago del Estero. Todas pertenecen a familias de bajos recursos, por lo que la prostitución constituye una alternativa para obtener dinero. No se encontró en la provincia alguna persona trans que pertenezca a otro nivel socio económico. Desempeñan diversos oficios $y$ profesiones: administración, docencia, peluquería, cosmetología y prostitución. Solo una de las entrevistadas es docente. Algunas de ellas también desarrollan acciones de movilización trans y políticas partidarias paralelamente a otras actividades de sostenimiento.

En este contexto, se puede decir que la familia y la escuela son reproductoras del orden heteronormativo esto se refiere al orden construido a partir del sistema binario varón-mujer. Por lo que, las personas trans al no ajustarse a las normas quedan fuera de los sistemas siendo humilladas, maltratadas, rechazadas y expulsadas. En consecuencia, ingresan a la prostitución siendo ésta un medio de supervivencia y al mismo tiempo un espacio donde pueden expresar libremente su identidad. En este contexto, la educación sexual integral desde la perspectiva de género cobra sentido, en tanto, formación indispensable para el desarrollo integral de las personas.

\section{Trayectorias Educativas en el Ámbito Familiar}

La familia es un ámbito donde las niñas y los niños experimentan sus primeras socializaciones, que más tarde se complementan simultáneamente con la que reciben en las instituciones educativas. En este contexto, la sexualidad es parte del proceso educativo tanto de la familia como de la escuela. Tal es así, que se educa sexualmente, aún cuando, en la familia se cree que es un tema tabú, reconocido como una cuestión para dialogar con adolescentes o resulte difícil hablar con los/as hijos/as.

En estos últimos años y luego de un proceso de cambio, se ha modificado el modelo de familia, la cual varían según el contexto sociocultural en que se encuentra inmerso. La organización familiar en nuestra sociedad está condicionada por el sistema sexo/género, es decir por un conjunto de normas y disposiciones por las cuales el sexo de las personas y su procreación es moldeada por la intervención social y compensada de una manera convencional (RUBIN citada en LAMAS 1987). Es un conjunto de discursos, símbolos, prácticas y representaciones sociales que la sociedad hace a partir de

Irma Elizabeth Chazarreta 
las diferencias biológicas y se ve plasmadas en las relaciones sociales de las personas en tantos seres sexuados.

La mayoría de las familias se basan en este sistema para educar a los niños y a las niñas. Desde muy pequeños incluso antes del nacimiento presentan espacios y colores para cada uno/a; se les enseña las cosas de varones y las de mujeres, las formas de hablar, de caminar y de sentarse. Se espera que las mujeres sean del ámbito privado, es decir que se ocupe de los quehaceres domésticos, de la crianza y el cuidado de los/as niños/as. Mientras, que a los varones se les concede la responsabilidad del sustento y cuidado del grupo familiar, y cumplir con el rol de proveedor trabajando fuera del hogar. Estos roles en los últimos tiempos han cambiado, porque la división sexual del trabajo lo ha hecho también, lo que no quiere decir que lo anterior no exista. En consecuencia, se ha impuesto, la doble presencia de las mujeres: en la familia y en el mercado laboral.

Por otra parte, la ley del matrimonio igualitario ${ }^{2}$ ha generado un cambio en la estructura familiar y ha logrado que hoy exista una ideología menos represiva en lo que respecta a la diversidad sexual; no obstante, no deja de estar presente en el imaginario social la idea de la familia patriarcal y heterosexual. En este sentido Maffia (2013) acierta al señalar que en el campo de la diversidad sexual existen injusticias derivadas de la heterosexualidad obligatoria, es decir las que tienen que ver con las jerarquías construidas en torno a la dicotomía homosexualidad y heterosexualidad las cuales suelen afectar a lesbianas, gays y bisexuales. Y las injusticias originadas por la normatividad de género, es decir, las relacionadas con la oposición y complementariedad entre la masculinidad y la feminidad, que impactan especialmente en las vidas de las personas trans.

Estas últimas, constituyen un grupo que rompe con las estructuras establecidas entre ellas el esquema binario mujer-varón; ya que manifiestan desde niños conductas y comportamientos diferentes a los mandatos sociales, provocando crisis en las familias. Algunos de esos comportamientos lo podemos mencionar a través del relato de una de ellas, como lo es el de Rosa quien menciona lo siguiente: "yo tengo recuerdo que nunca he tenido amigos varones, no me gustaba jugar a la pelota. Todas mis amigas eran mujercita.....yo jugaba con las mujeres, jugaba con las muñecas, me pintaba, hacia cosas propias de las mujeres". En otras palabras y siguiendo a Fernández (2004) se puede señalar que los gustos determinados por los juegos y deportes, la selección de prenda de vestir, las preferencias sexuales son motivos que circulan en el entorno de las personas trans y de las que empiezan a autopercibirse con una identidad que es contraria a la socialmente esperada.

Estos comportamientos se ven perturbados por la influencia de la familia: en algunos casos provoca que los niños duden de lo que sienten, les gusta o lo que desean, mientras que otras se mantienen firmes y enfrentan las dificultades. En este contexto, la palabra encontrada para dar cuenta de la diferencia es la homosexualidad, entonces es la que utilizan para ser identificadas, mientras, se ensayan representaciones del género femenino (FERNÁNDEZ, 2004). Cuya identidad de género es considerada en la familia

2 Ley No 26.618, de 2010.

Irma Elizabeth Chazarreta 
Trayectorias Educativas de las Personas Trans em Situación de Prostituición:

Dilemas y Desafíos em el Norte Argentino

una perversión o una enfermedad, definición que produce marcas en los pequeños que los acompañan hasta convertirse en personas adultas o durante toda la vida, mediante perturbaciones, sentimientos de desazón, de culpa y baja autoestima. Dicho esto, resulta significativo mencionar la palabra de las protagonistas principales:

En mi familia lo que soy era mal visto, era una desviación, yo no lo entendía así [...] quizás en toda mi adolescencia si le he creído eso y he vivido una adolescencia triste por el hecho de ver mi identidad sexual como una perversión, porque era lo que me mostraba mi familia, en grande me he dado cuenta que no era asi [...].(Rosa, 2013).

[...] en mi casa cuando mi mamá se ha enterado... primero le dije que me gustaban los hombres y después empecé a transformarme. Y a mi mamá no le gustaba eso. Yo salía con mi ropa y me cambiaba en el monte para ir a bailar. Entonces mi mamá me empezó a mezquinar todo diciendo para que yo no use nada. Mi mamá me hacia la vida negra, la vida imposible [...] (Betty, 2014)

Ha sido para mí un calvario asumir mi homosexualidad porque era yo contra el mundo. Y me dolía mucho, yo sentía que he desilusionado a mi familia obviamente a mi madre. Yo intentado cambiar y decir que era un hombre, y no he podido... me hecho tratar... le he pedido a mi madre que me ayude, me ha llevado a un sicólogo, un médico... ambos le han terminado diciendo que lo mío no era una enfermedad. (Madelyn, 2013).

Los intentos familiares por buscar una solución al problema del niño diferente también han sido analizados por Josefina Fernández en su libro Cuerpos Desobedientes. En el cual todas las entrevistadas que forman parte del mismo "manifiestan haber sido llevadas a una consulta médica y/o psicológica y, aún cuando no se les revelara los motivos de ello, todas afirman que estuvo relacionada al conflicto que ellas generaban en la familia" $(2004$, p. 81).

Estas situaciones hacen que muestren lo que las personas trans llaman doble personalidad; es decir, por un lado revelar que son varones tal como las normas sociales lo establecen y por otro lado, ocultar los deseos, gustos y preferencias que no corresponden con el género que la sociedad espera. En otras palabras y de mano de las protagonistas quienes señalan que "para evitar ser aislada por nuestras familias a menudo soportamos la falta de reconocimiento de nuestra identidad. En estos casos, el costo de permanecer en contacto es soportar la violencia de ser tratadas como varones" (BERKINS 2007, p. 70).

El castigo, el hostigamiento, la falta de comprensión, el rechazo son motivos muchas veces de alejamiento de los hogares, el cual ocurre alrededor de trece a dieciocho años (BERKINS 2007). Durante esa edad o más tarde, vivencian el proceso de transformación siendo lo mas traumático para la familia ya que se hace visible ante la mirada moralista de la sociedad. Allí incorporan lo que Fernández (2004) llama marcadores corporales de la 
Trayectorias Educativas de las Personas Trans em Situación de Prostituición:

Dilemas y Desafíos em el Norte Argentino

feminidad y renuncian a otros que les han sido asignadas, de ese modo se autoasignan un género femenino como única opción en una sociedad dicotómicamente. En este sentido una de las chicas trans menciona lo siguiente:

[...] a partir de que yo me he transformado en una mujer trans, yo nunca más he podido ir a visitar a mi familia de la Rioja, porque mi madre no me llevaba y mi familia de allá no quería que vaya, hasta el día de hoy [...]. (Rosa, 2013).

Como se ha mencionado antes, estas personas en el ámbito familiar a diario experimentan situaciones de humillación y de violencia, hasta la expulsión de la familia. Sin embargo, cabe aclarar que no todas corren la misma suerte, sino por el contrario, algunas encuentran allí un espacio de contención y cooperación, tal es el caso de Madelyn que en una primera instancia, en la que ocultaba su identidad de género tenía una cómplice en la familia:

[...] mi hermana siempre ha estado a la par mía emm...con sutiliza, ósea nunca ha dicho yo te apoyo eh...ella se daba cuenta y me decía...como por ejemplo...eh...no se te nota mucho?, agarra...cuando venga lávate bien la cara con jabón, me entiende? o...ese lápiz es muy cremoso usa este...este es mejor entiendes?, no me decía directamente ella venia con sutiliza y me decía...me prestaba su ropa [...]. (Madelyn, 2013).

En una segunda instancia cuando decide expresar sus sentimientos, deseos a su madre, también recibe un apoyo incondicional y consejos:

yo lo único que te pido es que te cuides...que te cuides y...perde cuidado que aquí...de aquí nadie te va a echar por lo que sos...vos te sientes así...bueno está bien...pero yo prefiero que respetes, me respetes a mí y a mi familia, que te cuides mucho, de ahi vos sabrás que vas hacer en la calle [...]. (Madelyn, 2013).

En este contexto, la familia es un lugar donde se respeta la decisión del otro, donde se respeta la identidad del otro. Evidentemente si comparamos la realidad de Rosa con la de Madelyn, se puede decir que las repercusiones en ellas es diferente, con respecto a la última, el apoyo familiar ayuda a enfrentar con seguridad y firmeza otros ámbitos: escolares, institucionales y sociales. Sin embargo, quien no tienen este apoyo debe afrontar sola, aislada y siendo aun más vulnerables. Recorridos que produce en ellas signos y marcas que las acompañan toda la vida a través de malestares innecesarios por la identidad de género.

La Escuela como Productora y Reproductora de Discursos y Prácticas en torno al Género

Las instituciones educativas en particular las escuelas son el segundo 
Trayectorias Educativas de las Personas Trans em Situación de Prostituición:

Dilemas y Desafíos em el Norte Argentino

espacio de socialización de los/as niños/as y jóvenes; en estas circunstancias hacen su aporte en la construcción de las identidades. Al mismo tiempo, son una de las principales fuentes de la información (socialmente legitimada) que reciben los niños/as junto a la familia, amigos/as y los medios de comunicación social. Además, las escuelas son lugares donde los estudiantes pasan una parte del día y del año; por lo que, es casi imposible disociar a ésta de aquellos acontecimientos cruciales en la construcción de la subjetividad de las personas en la sociedad.

La escuela lejos de ser una ambiente amigable para los/as estudiantes con identidades diferentes a lo normativo es uno de los ámbitos de exclusión para las personas trans, por parte de sus pares, educadores/as, y tutores/as; estos últimos muchas veces son quienes aconsejan a sus hijos e hijas que no creen vínculos con estas personas. Las instituciones educativas en sí excluyen a estas desde el inicio, porque "producen un trabajo sobre los cuerpos en práctica que marcan oposiciones simbólicas de género" (MORGADE, 2008, 177). Esto se ve a simple vista mediante la división de los baños, las filas de los niños y de las niñas, las normas de vestimentas, apariencias aceptables y no aceptables, el uso del cuerpo en clases y recreos (MORGADE, 2011). Las voces de quienes pasaron por este contexto resultan significativas para comprender mejor la situación:

En la secundaria ha sido desastrosa, no encuentro otra palabra para decirte, los compañeros suelen ser muy crueles: te ponen apodos te dicen cosas, se burlaban de mi,....en la escuela han visto que yo tenía buenas notas y no sabian que era yo y han dicho este es el abanderado... pero yo de entrada dije que no me voy a poner corbata, ni me voy a poner camisa, asi que he rechazado la bandera [...]. (Rosa, 2013).

[...] He dejado el secundario...porque he tenido problema con el preceptor, me he ido a quejar que en el momento que iba al baño, sentía presión de mis compañeros, y el preceptor decía que yo provocaba todo eso y me he ido reiteradas veces hasta que me he cansado... y he tenido que ir a estudiar otra cosa [...]. (Madelyn, 2013).

De esta manera, al interior de las escuelas se producen y reproducen los discursos y prácticas sobre la sexualidad y el género creando cuerpos e identidades desde la norma heterosexual; que luego son trasladadas a la sociedad en general. A través de esta reiteración de reglas se logra que los cuerpos e identidades sean vistos como un hecho natural y no como una producción social, cultural y pedagógica (MORGADE, 2008). La norma corporal es asumida y apropiada por cada persona que se constituye en virtud de haber atravesado este proceso de asumir un sexo (BUTLER, 2011) en la hegemonía del dominante que habilita cierta identificaciones sexuadas y desalienta otras.

Las escuelas, en tanto aparato ideológico, pretenden articular las identidades de género "normales" o "naturales" a un único modelo: el 
Trayectorias Educativas de las Personas Trans em Situación de Prostituición:

Dilemas y Desafíos em el Norte Argentino

heterosexual (LOPES LOURO, 1999), por lo que las personas trans generalmente no son aceptadas. En este contexto, ellas atraviesan una serie de situaciones que van desde rechazo, desprecio hasta diferentes tipos de violencias: física, psicológica y simbólica. Al respecto una de las informante menciona que "cuando iba al baño sentía presión de mis compañeros, en burlas, y en intención" (Madelyn). A causa de la violencia, tienen baja autoestima y se vuelven retraídas y sumisas; tal es el caso de Julieta quien "no salía a los recreos, me quedaba metida en el curso". Sumado a esto, la falta de contención y apoyo de la familia y la escuela hace que se tornen más vulnerables y expuestas; por lo que su identidad de género las expulsa del sistema y ven a la prostitución como la única actividad de supervivencia.

Con relación a la exclusión, en el documento "Hacia un plan nacional contra la discriminación. La discriminación en Argentina. Diagnóstico y propuestas", elaborado por expertos con participación de organizaciones de la sociedad civil y aprobado por el poder ejecutivo, como parte de los lineamientos del Plan Nacional contra la Discriminación se afirma que las personas trans viven su identidad como un desgarro. Mientras que el proceso de identificación sexual transcurre a lo largo de la infancia y adolescencia, las instituciones educativas y los/as docentes no tienen ningún tipo de formación para contener y acompañar a estas personas. Esto significa que la escuela tiene mucho que replantearse y no lo está haciendo o por lo menos no lo visualiza.

Esto produce marcas con las que tienen que cargar las personas, las cuales se ven explícitas en el cuerpo a través de las prohibiciones: de las ropas, maquillajes y accesorios. La mayoría de las veces no aguantan las interdicciones, las burlas y las discriminaciones por lo que abandonan la institución; sumado a esto la situación económica hace que deban recurrir a la prostitución como única labor posible por la condición de género, ya que el resto de la sociedad las excluye por los prejuicios existentes.

Mientras, que otras logran resistir el control y poder de las escuelas haciéndoles frente para conseguir el objetivo, que es continuar con la educación formal y trabajar en un futuro de otra actividad alternativa a la prostitución. Rosa es una de las que ha podido afrontar todos los dilemas tanto en la familia como en la escuela y la sociedad en sí, para lograr un desafío propuesto el de concluir una carrera universitaria. En esta etapa ha atravesado por la siguiente situación:

En la universidad si he tenido un poco más de apertura, digamos...e..., yo ya tenía muy asumida mi sexualidad. Entonces algunos profesionales este...muy buena onda me llamaban con mi nombre femenino, me trataban de ella,... y otros no. Y es feo escuchar todos los dias cuando toman la asistencia el nombre con el que no te sientes identificada, algunos lo entienden otros no, pero en ese momento...ya me dejo de molestar...de esos que no me entendian no es cierto?, pero la mayoría en la universidad me aceptaron, pero en ese nivel.... Y quizás por mi personalidad muy avasallante porque he tenido amigas mías que han ido a estudiar a la universidad y han dejado justamente por esa causa, porque se sentían este...discriminadas sobretodo en cómo llamarlas a ellas [...]. 
(Rosa).

Rosa es un ejemplo de perseverancia en el mundo académico donde su identidad de género, es poco respetada. En consecuencia debe soportar diferentes obstáculos como humillación y violencia, para obtener un título universitario que le posibilite ejercer una profesión; cuando todos y todas los/as ciudadanos/as tienen como derecho básico a la educación. Es necesario señalar que durante este proceso y luego de ser expulsada del ámbito familiar no tuvo otra opción que recurrir a la prostitución como recurso para solventar sus gastos. Actividad que realizo hasta terminar la universidad, y es hoy la única profesional trans en Santiago del Estero, lo cual es un ejemplo y orgullo para sus pares.

La visión dicotómica disponible en estos espacios sobre el género varón/mujer se toman como legítimos, y se posicionan desde la moral para juzgar a quienes no se encuentran dentro de la norma heterosexual. En este sentido, la agresión emocional, la coacción moral, la sospecha, la intimidación, la condenación de la sexualidad, la desvalorización de las mujeres y de las personas trans de acuerdo a su personalidad, su cuerpo, sus actos, su valor moral, es lo que llama Segato (2003) violencia moral. Ésta es la más eficiente de los mecanismos de control social y de reproducción de las desigualdades; asimismo es la más sutil, ya que no hace falta una agresión verbal sino sucede a través de los gestos, miradas o actitudes.

Una propuesta para contrarrestar las situaciones de desigualdad y de violencia en las escuelas lo constituye la reciente aprobación de la ley contra el bullying ${ }^{3}$ que promete la promoción de la convivencia y el abordaje de la conflictividad social en las instituciones educativas. Asimismo, promueve el respeto, la aceptación de las diferencias, la resolución pacífica de los conflictos, la apelación al diálogo y la contextualización de las situaciones de violencia. Esto implica un desafío de todos los miembros de la comunidad educativa; esta ley, en particular propicia un fértil espacio de cooperación para el Instituto Nacional de contra la Discriminación, Xenofobia y el Racismo (INADI, 2013).

\section{La Prostitución como Única Opción para las Personas Trans}

Según Daich (2012, p. 8) "la prostitución no es un fenómeno unívoco, mucho menos uniforme y su heterogeneidad se complejiza con las diversas formas que la prostitución asume no sólo en distintos contextos y mercados, sino también en términos históricos y culturales". En este sentido, es trascendental señalar que es diferente la realidad que vivencian las mujeres que ejercen la prostitución por elección ante una variedad de ofertas laborales, y las personas trans, que lo hacen como única labor posible de realizar por su identidad de género.

En relación a esto último, Lohana Berkins postula lo siguiente:

3 Ley N ${ }^{\circ} 26892$-Ley para la Promoción de la Convivencia y el Abordaje de la Conflictividad Social en las Instituciones Educativas, -Ley contra el 'Bullying'- Sancionada el 13 de septiembre del 2013. 
Trayectorias Educativas de las Personas Trans em Situación de Prostituición:

Dilemas y Desafíos em el Norte Argentino

[...] Es el estado quien nos condena a sobrevivir de la prostitución. El único medio de supervivencia que tenemos es la prostitución. Por lo tanto para nosotras, más allá de las condiciones, si son precarias o no, o en las condiciones en que se establezcan, no es un trabajo. Para nosotras va a ser un trabajo, cuando tengamos alternativa de elección. Cuando digamos, por ejemplo, "ya soy oficinista gano tanto, pero en la esquina gano mucho más...". Entonces si consideraríamos que es un trabajo que se puede elegir (BERKINS y KOROL 2006, p. 16).

Al señalar que la prostitución es un fenómeno heterogéneo y que varía en diferentes contextos, podríamos pensar que como única alternativa de supervivencia en las personas trans es exclusivo de nuestro país. Sin embargo, en Brasil de acuerdo a la investigación realizada por CABRAL, SILVA, ORNAT (2013) en "Espaços de Morte e Representações Sociais deTravestis na Cidade de Ponta Grossa- Paraná" (Brasil) señalan que la mayoría de las travestis que forman parte de ese trabajo, tienen a la prostitución como única ocupación posible después de haber sido excluidas de la familia. En ese contexto, aparece la prostitución como resultado de cierre en varios espacios (familia, escuela, hospitales entre otros) a lo largo de la vida, donde se les prohíbe la entrada a causa de las representaciones sociales que existe en Ponta Grossa sobre las travestis. La coincidencia está relacionada a la heterosexualidad como práctica dominante en la cultura moderna occidental que no solo define las acciones de las personas en el espacio privado sino que establece relaciones de poder que operan en todos los espacios cotidianos e invisibiliza, excluyen y marginan a quienes la transgreden.

Esta realidad, tiene su correlato en Santiago del Estero, donde las personas trans recurren a la prostitución como único modo de supervivencia y además, constituye uno de los escasísimos espacios de reconocimiento de la identidad travesti como una posibilidad de ser en el mundo (FERNÁNDEZ 2004). Allí lo femenino se somete a los deseos de los varones quienes según el imaginario colectivo tienen el poder económico y sexual. Una de las protagonistas relata lo siguiente:

He buscado trabajo... y el único lugar donde una chica trans era aceptada era en la calle...yo he preferido ir a la calle con tal de no dejar de ser yo misma, de ponerme la pollerita que yo quería, de pintarme, de dejarme el pelo largo, y ser la mujer que hoy soy... (Rosa).

[...] estoy mirando de que más adelante cuando tenga que dejar la calle no sé que voy hacer....estoy buscando por otro lado, el tema es ahorrar y ver que puedo lograr con eso... Tengo algunos proyectos a ver si se me da, sé que un día la calle me va a cerrar las puertas también... por la edad, y porque los clientes buscan chicas jóvenes [...]. (Madelyn, 2013).

Los prostituyentes buscan mujeres y trans jóvenes cuyo cuerpo despierten el deseo, por lo cual deben mantenerse dentro de los cánones de belleza y

Irma Elizabeth Chazarreta 
juventud impuestos por los modelos sociales. Con el fin de perseguir esta belleza se exponen a cirugías, a la implantación de siliconas o a la inyección de aceites para mejorar su aspecto, prácticas realizadas por lo general sin condiciones médicas seguras. Este equilibrio, entre el cuidado del propio cuerpo y la utilización del mismo para el trabajo sexual, conlleva implícita una tensión de difícil resolución, situación que lo expresa claramente Rosa:

Lo que cuidas es la estética, no la salud. Te preocupas por estar linda, por verte bien, pero no por sentirte bien, ni por comer bien, ni alimentarte bien, ni por llevar una vida saludable. Te preocupas por tener unos lindos pechos, tener un buen pelo y estar bien pintadas, lo que importa es como producto no como persona.

En lo que respecta a la tarea de la noche, la herramienta de trabajo de ellas, es el propio cuerpo que se expone cotidianamente a diferentes situaciones de riesgo que van desde la transmisión de una infección sexual, hasta diversos tipos de violencia. Ante la realidad, se les torna difícil las prácticas de autocuidado y sobre todo si se trata de ir a los centros de salud, en la que no hay correlación entre los horarios de sus trabajos con la atención de los servicios de salud públicos. A ellos hay que recurrir en las horas tempranas para sacar turno, cuyo horario es incompatible con el ejercicio de la prostitución. Si tuvieran que elegir entre estas dos opciones sin duda alguna, optarían por la última.

La violencia contra las personas trans en situación de prostitución hace que se sientan menospreciadas ante sí mismas y las demás. De igual manera atenta contra su identidad puesto que refuerza y reproduce la subordinación de lo femenino. La violencia contra ellas pone en riesgo su derecho a la vida, a la libertad y a la seguridad personal. Pues en algunos casos son asesinadas por el tipo de ocupación que realizan: el ejercicio de la prostitución y que además son aun más vulnerable al realizar una tarea destituida o estigmatizada, aunque para el consumo no es vista de la misma forma.

De ese modo, los prostituyentes conocidos tradicionalmente como clientes, son seres anónimos, comunes e invisibles. Se los muestra como seres inocentes, víctimas ante el estímulo y la facilitación de tanta oferta; lo que refuerza el estereotipo de la sexualidad como expresión de la naturaleza de los varones (VOLNOVICH, 2010). Tal es así, que el cliente pretende vivir su vida, satisfacer sus necesidades y sus fantasmas, como una curiosidad o como una relación sin compromiso (CHEJTER, 2011).

\section{Algunas Consideraciones Finales}

En las familias y en las escuelas se sostiene un discurso hegemónico y relativo que mediante las relaciones de género tienden a legitimar la feminidad y la masculinidad tradicional. Los temas referidos a la sexualidad son censurados sistemáticamente por los adultos y también por los y las adolescentes. Las personas trans son maltratadas, humilladas, excluidas y expulsadas de los sistemas: familiares, educativos, laborales y sociales. Por lo que recurren a la prostitución como única actividad posible de realizar por la 
identidad de género; la cual, no constituye una elección sino una obligación personal y familiar en algunos casos para la supervivencia. Donde allí también se mantienen relaciones de subordinación y dominación de los prostituyentes sobre en lo femenino.

Las trayectorias educativas de las personas trans se encuentran atravesadas por el sistema sexo-género; pues reciben educación a partir de prácticas culturales rígidas y estructuradas que moldean la identidad, el comportamiento de ellas, de las cuales se cree que es natural y se la reproduce. Los significados adquiridos en torno al género producen vivencias y marcas en los cuerpos difíciles de borrar. Por lo anterior, resulta significativo develar estas situaciones, para desnaturalizarlas; asimismo, es importante en otra instancia analizar las políticas del Estado y responsabilizarlo de estas cuestiones para pensar cómo avanzar en la lucha por el derecho de las personas trans.

Frente a esta situación resulta importante insistir en la aplicación de la ley $\mathrm{N}^{\mathrm{o}} 26150$ educación sexual integral, en donde se impartan conocimientos acerca del propio cuerpo, sus derechos a la salud, a la identidad, la no discriminación, el buen trato y la información. En efecto, que la escuela sea un lugar donde los/as niños/as y jóvenes puedan asumir valores y actitudes responsables relacionadas con la sexualidad; espacio compartido y asumido por las familias durante la etapa escolar de los/as estudiantes. Ambientes propicios para la transformación de prácticas culturales fuertemente arraigadas y erradicar desigualdades que obstaculizan el desarrollo de los y las educandos/as.

\section{Referencias}

BERKINS Lohana (compiladora) Cumbia, copeteo y lágrimas. Buenos Aires: ALITT Asociación de lucha por la identidad travesti y transexual, 2007.

BERKINS, Lohana y KOROL, Claudia (Coord.) Diálogo prostitución/trabajo sexual: las protagonistas hablan. Buenos Aires: Editorial Feminaria, 2006.

BOURDIEU, Pierre. El sentido Práctico. Buenos Aires: Siglo XXI, 2007 [1980].

CABRAL, Vinicius, SILVA, Joseli Maria, ORNAT, Marcia. Espaços de Morte e Representações Sociais deTravestis na Cidade de Ponta Grossa- Paraná. Revista Latino-americana de Geografia e Gênero, v. 4, n. 1, p. 139 - 161, 2013.

CHEJTER, Silvia. Lugar común: la prostitución. Buenos Aires: EUDEBA, 2011.

DAICH, Deborah. ¿Abolicionismo o reglamentarismo? Aportes de la antropología feminista para el debate local sobre la prostitución. Runa 'Archivos para la Ciencia del Hombre', v. XXXIII, n. 1, p. 71 - 84, 2012.

FERNÁNDEZ, Josefina. Cuerpos desobedientes: travestismo e identidad de 
Trayectorias Educativas de las Personas Trans em Situación de Prostituición:

Dilemas y Desafíos em el Norte Argentino

género. Barcelona: Edhasa, 2004.

INADI. Mapa Nacional de la Discriminación. Segunda serie de estadísticas sobre la discriminación en Argentina. Buenos Aires: $1^{\mathrm{a}}$ de, 2013.

Ley $N^{\circ}$ 26892. Ley para la Promoción de la Convivencia y el Abordaje de la Conflictividad Social en las Instituciones Educativas. Ley contra el 'Bullying'- Sancionada el 13 de septiembre del 2013.

Ley Nacional № 26743. Ley de identidad de género. 2012.

Ley Nacional No 26.618. Ley de Matrimonio igualitario. 2010.

Ley Nacional de 26150. Educación sexual integral. 2006.

MAFFIA Diana. Conferencia: Desafíos de las familias diversas, nuevos reconocimientos de género y demandas en la Justicia. Observatorio de Género en la Justicia. Consejo de la Magistratura de la Ciudad Autónoma de Buenos Aires, 2013.

MORGADE, Graciela; ALONSO, Graciela. Cuerpos y sexualidades en la escuela. Buenos Aires: Paidós, 2008.

MORGADE, Graciela (compiladora) Toda educación es sexual: hacia una educación sexuada. Buenos Aires: La Crujía, 2011.

LAMAS, Marta. La antropología feminista y la categoría género. Revista Nueva Antropología, n. 30, p. 173 - 198, 1987.

SEGATO, Rita. Las estructuras elementales de la violencia. Bernal: Universidad Nacional de Quilmes / Editorial Prometeo, 2003.

VOLNOVICH, Juan Carlos. Ir de putas. Reflexiones acerca de los clientes de la prostitución. Buenos Aires: Topia Editorial, 2006.

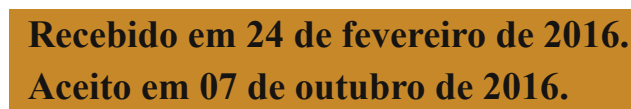

Irma Elizabeth Chazarreta 